\title{
Method and Device for Improving the Utilization and Operating Efficiency of Submersible Pumping Equipment
}

\author{
Oybek Kurbonov Mukhammatkulovich \\ Navoi State Mining Institute, Republic of Uzbekistan
}

\begin{abstract}
The paper considers the issues of increasing the coefficient of utilization and efficiency of submersible pumps operation. The research of arising problems due to abundant gassiness and content of solid particles in the liquid during the operation of submersible pumps in geotechnological wells has been carried out.

An analysis of various methods and devices for combating sanding and gasiness in wells has been performed. Descriptions, design elements, principle of operation and technical and economic indicators of the developed technical solution are given. Presents schematic diagrams of the construction of the device to combat sand and gas in the production wells.
\end{abstract}

Key words: efficiency, utilization factor, submersible pumps, centrifugal pumps, sand formation, well, gas content, energy consumption, productive solution, hydrostatic pressure, hydrodynamic pressure.

\section{INTRODUCTION}

In the process of development of the mining industry of the country, in parallel with the increase in the depth of processing and requirements to improve the purity of the final product, the requirements to the ecology and safety of the used equipment have become stricter.

Submersible centrifugal pumps form a group different in design from conventional pumps with a horizontal shaft. The vertical location of the pump in the well predetermined the design solutions such as hydraulic load perception, bearing arrangement and lubrication, configuration and dimensions of pump parts, and their layout [1].

Sand and other impurities constantly rise from the well together with the liquid, prevention of clogging of the pump and other technological equipment is possible on the basis of filtration of sand and other impurities. Submersible pumps when pumping liquids with large amounts of impurities overheat and wear out in a short period of time. The increase in a share of sand in a liquid, leads to frequent breakdowns of the submersible pump units [2].

\section{PURPOSE OF WORK}

The purpose of this research is to improve the efficiency of electric submersible pumping units in geotechnological wells with viscous, highly gassy and solids fluid.

\section{PROBLEM DISCUSSION}

The main causes of problems in the operation of submersible electric pumping equipment:

- failure to comply with the rules of well construction and casing the wellbore;

- incorrect installation of strainers;

- destruction of the very construction of the wellbore for various reasons;

Failure to comply with the rules of drilling lead:

First, drilling deviates from the vertical in the process of penetrating the rock. The wellbore turns out to look like a bent worm. The casing that is deposited in such a borehole experiences unequal loads. As a consequence, pipe depressurization can occur, both during and after drilling. Sometimes the change of wellbore design and depressurization of casing occurs 1-2 years after putting them into operation.

Secondly, low-quality materials can be used during drilling operations. Poor-quality plastic pipes, not adapted to the soils, can cause that the well will be sucked up by slurry from the water-bearing sand layers $[6,11]$.

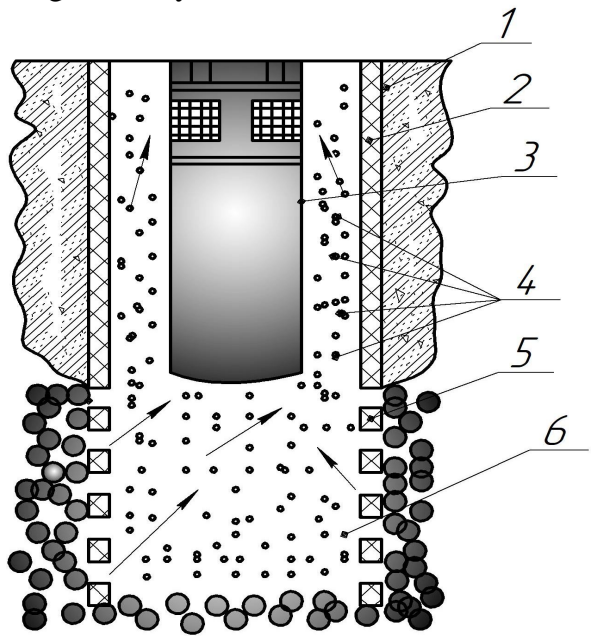

Figure 1: The process of sanding the well: 1-borehole, 2-casing,

3-submersible pump, 4-sand particles, 5-well strainer, 6-productive formation 
Performed analysis of operation of submersible pumping equipment of underground mining leaching mines has identified the main causes of the following problems:

- vibration occurs in the pumping equipment due to the presence of gases and solids in the liquid, the motor disconnects from the pumping part, breaks out at the bottom of the well and puts the well out of service;

- premature failure of pump impellers due to the presence of gases and solids in the liquid, making the pump equipment unusable;

- efficiency of pumping equipment is reduced due to gases and solids in the liquid;

- energy consumption increases during pumping operation due to gases and solids in the liquid;

Improving the efficiency of pumping equipment is solved on the basis of the development of a method and device to combat sand and gas in the well $[8,10]$.

\section{MATERIALS AND METHODS}

As a result of the research, a technical solution to combat sand and gas content in geotechnical wells was developed.

The developed method and device can be used for hydraulic borehole development of deposits, to control sand and gas content in wells.

To date, known several ways to combat sand and gas in geotechnological wells on production conditions. One of them is application of gas separator for submersible pumps, which consists of tubular body with head, base with receiving net and shaft with parts located on it. The head has two cross channels for gas and liquid. The base contains a mesh-enclosed cavity with channels for receiving gas-liquid mixture with solid particles. The shaft contains a heel, a screw, an axial impeller, a separator. The body contains a guide grid and sleeves [4].

However, the gas separator device is a complex construction and in the process of operation under extreme conditions, the reliability of operation decreases.

Another way to combat sand formation in wells is to equip wells with a sucker-rod pump. The method provides a constant rate of formation fluid inflow due to smoothing pulsations of the sucker-rod pump pressure transmitted to the bottomhole zone through the borehole fluid. To implement the method, the amount of sand carried out of the pay zone, the dynamics of pressure changes in the bottomhole zone and borehole space during the operation of the rod pump, the rate of formation fluid and borehole fluid, geological properties of the reservoir are evaluated. Based on the evaluation, the length of the intake string, the cross-section of the passage channels, the number of pockets and the volume of elastic reservoirs are determined [5].

The unit includes a receiving column placed under the intake of the rod pump, along the length of which pockets are installed. Each of the pockets is formed by the inner surface of the receiving column and a cofferdam with a passageway. The pockets contain elastic, leak-proof gas-filled vessels.
But when operating the device, regular cleaning of pockets and flushing of well sump from accumulated sand is required, which creates difficulties in application of this method.

Another closest analog is a method and device for combating sand formation in wells equipped with a sucker-rod pump, including running the casing string and its cementing to the wellhead, lowering a perforated liner or filters into the well in the productive part of the formation, followed by running the processing string, in which the flushing fluid is pumped. Pumping equipment is run in the well in parallel to the production string and the production string is run to the bottom of the well. Before lowering into the well in the process casing at the place of its location in the productive layer section, perforation holes are made, and at the end of the casing a plug is installed, flushing fluid is pumped into the process casing cyclically with the pumping equipment running [7].

However, the method involves the use of regular flushing of the technological column and perforation holes, which increases labor intensity and reduces the efficiency of its application.

\section{RESULTS AND DISCUSSION}

To solve the above-mentioned problems, we set the following task, which involves improving the efficiency of electric submersible pumping units, operated in geotechnological pumping wells.

The set task is solved on the basis of developing a method of combating sanding and gassiness.

In our development the submersible pump is placed at the bottom of a blind tube, cone-shaped guides are placed over the suction nozzle of the pump unit at an angle of $45^{\circ}$.

The proposed method and design of the device allows the separation of gas-liquid mixture with solids when entering the device into three flows: gas, liquid and solid particles with their direction by their movement channels due to the action of gravity and pressure difference in the points of change of direction of the liquid mixture flow. Upward movement of gas bubbles outside the device and withdrawal of solids to the bottom of the well, reduces the possibility of clogging and abrasion of the device and submersible electric pumps, which increases the reliability of their operation.

This creates two flow paths for the movement of the productive mud: upward between the dead pipe and the casing, and downward between the electric pump unit and the dead pipe.

In addition, a cone-shaped guide is attached above the suction pipe of the electric pumping unit to change the direction of the productive solution movement by $145^{\circ}$. The height of the blind tube exceeds the submerged electric pump unit by $40-50$ $\mathrm{sm}$, which contributes to the movement of the productive solution in the space between the electric pump and the tubular column, changing the direction of movement by $180^{\circ}$ downward. 
Figure 2 shows a device for combating sand and gas formation in geotechnical wells equipped with a submersible electric pumping unit.

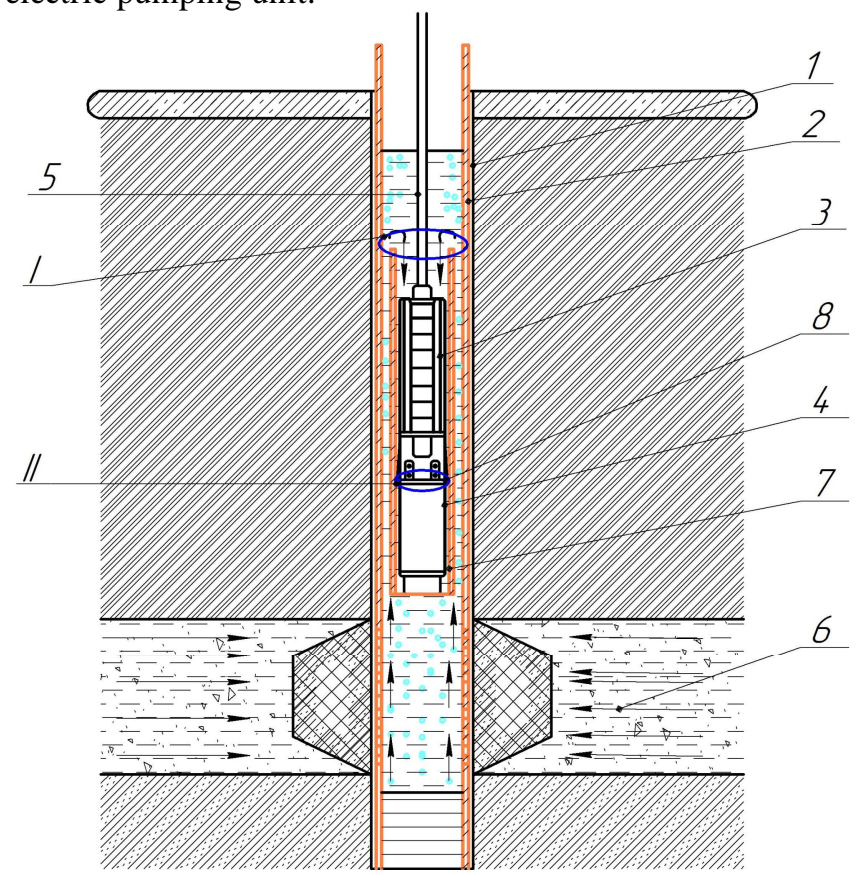

Figure 2: Device for combating sanding and gas content in geotechnological wells equipped with a submersible pump. 1 - mud well, 2 - casing, 3 - submersible pump, 4 - submersible pump motor, 5 - mud tube, 6 - pay formation, 7 - tubular string, 8 - flow guide device

The device contains a mortar well (1), a casing pipe (2), a submersible electric pump (3), a submersible electric pump motor (4), a mortar-lifting pipe (5), a productive formation (6). The submersible electric pump unit is placed inside a special tubular column (7) and a disc-shaped flow guide device is attached to the pump at the pump inlet at $45^{\circ}$ to its axis (8). The pump unit is attached to the bottom of the developed blind tube, with its height exceeding the height of the pump unit by $40-50 \mathrm{sm}$. There is a $50-100 \mathrm{~mm}$ diameter gap between the pump unit and the blind tube for vertical downward movement of pregnant fluid. Between the dead pipe and the casing also leaves a gap for vertical lifting of productive mud under hydrostatic and hydrodynamic pressures of the well.

Figure 3 shows the scheme of the device and the points of separation (point I, point II) of the gas-liquid mixture with solids into three streams: gas, liquid and solid particles with their movement through their channels due to changes of direction by the combined action of gravity and the difference of hydrostatic and hydrodynamic pressures at the points of flow direction of the liquid mixture at $180^{\circ}$ and $145^{\circ}$ degrees.

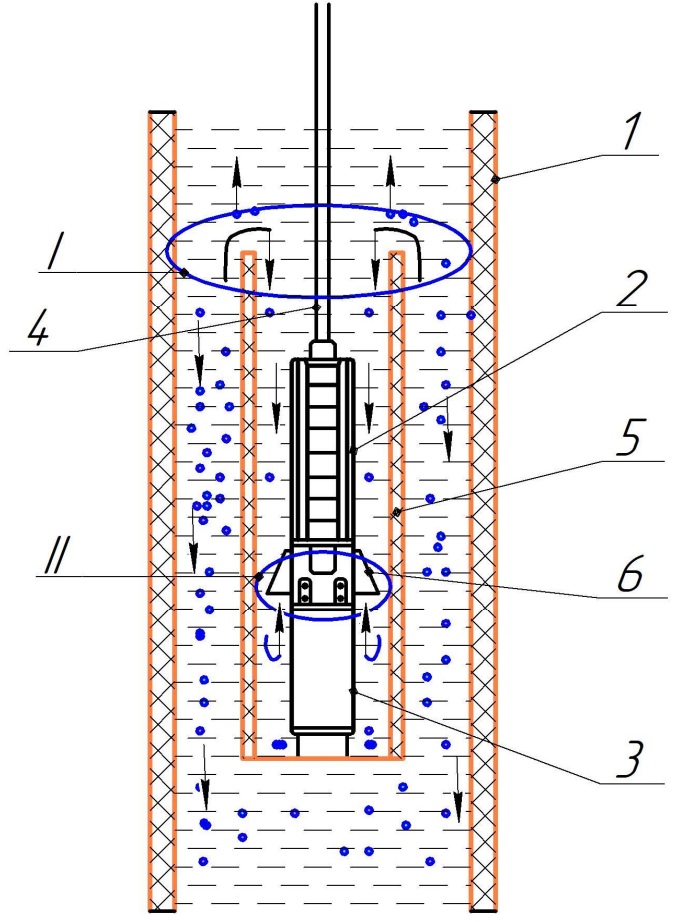

Figure 3: Device for combating sanding and gas content in geotechnical wells equipped with a submersible pump.

1 - casing pipe, 2 - submersible pump, 3 - submersible pump electric motor, 4 - mud tube, 5 - tubular string, 6 - flow device guide

The device for combating sand formation and gas content works as follows: productive solution containing gas and solid particles through the filtered zone enters the borehole cavity and rises upward under the action of hydrostatic and hydrodynamic pressure. As the solution moves upward, some of the solids are partially deposited at the bottom of the well under the action of gravity (density) forces.

Productive solution enters the pipe space between the blind pipe and the electric pump unit, and then under the action of pump suction it moves downward. At the same time the direction of flow of the solution changes by $180^{\circ}$. Due to the change in direction of the flow the gaseous products are removed upwards and the solution is partially separated into solid and liquid phases. The pregnant solution enters the suction branch of the pump unit through the guide device, installed at $45^{0}$ to its axis. At the same time there is a secondary separation of the solution flow into solid and liquid phases with the appropriate direction of movement [9]. In order to determine the effectiveness of the proposed device to combat sand and gas leakage, we conducted experimental work, which were carried out on the stand, the figure of which is shown in Fig. 4. 


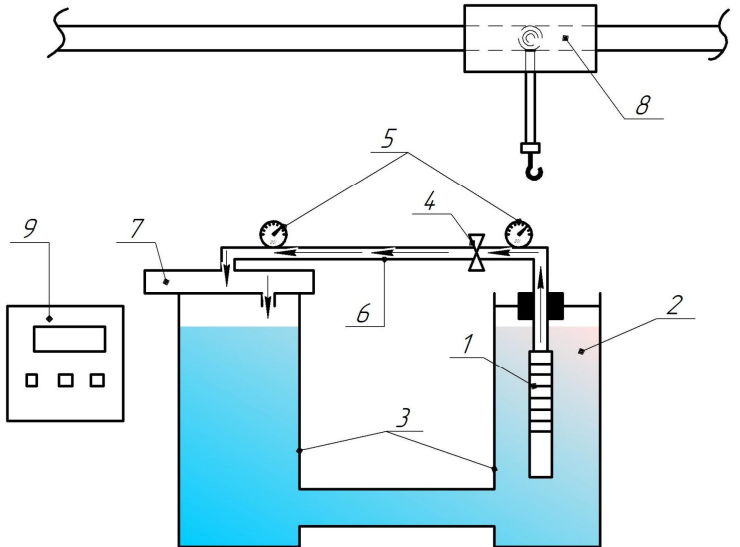

Figure 4: Test Bench for Submersible Pumps. 1 - USK 408/42 submersible pump; 2 - Water; 3 - Two communicating vessels; 4 - Valve; 5 - Manometer; 6 - Pipework; 7 Pump performance measurement tank; 8 - Gantry crane; 9 - Control station.

The results of the performed experimental studies allowed us to obtain the dependence of pump power consumption on pump delivery in conventional layouts and the dependence of pump power consumption on pump delivery together with the developed device to control sand and gas content in geotechnological wells.

Figure 5 shows graphical dependence of pump power consumption on pump delivery with conventional submersible pump arrangement.

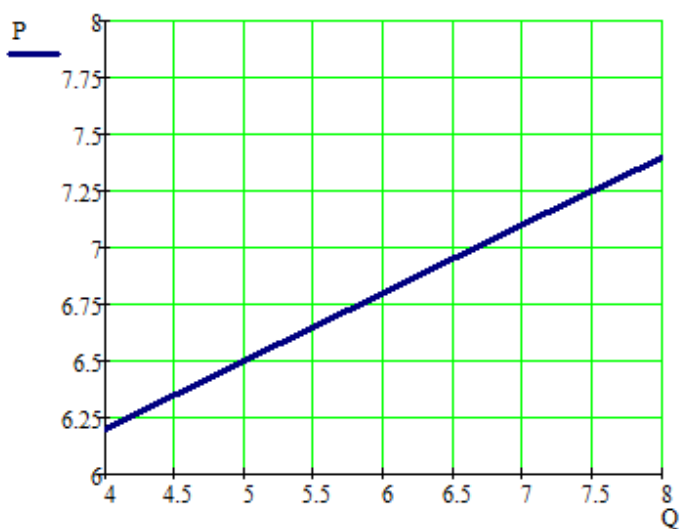

Figure 5: Graphical dependence of the pump power consumption $(\mathrm{P}, \mathrm{kW})$ on the pump delivery $\left(\mathrm{Q}, \mathrm{m}^{3} / \mathrm{h}\right)$ for a conventional layout.

Figure 5 shows that for every $4 \mathrm{~m}^{3} / \mathrm{h}$ increase in pump flow, the power consumption increases by $1.2 \mathrm{~kW}$.

Also in figure 6 shows the graphical dependence of the power consumption of the pump on the pump feed when using the developed device to combat sand formation and gas content in geotechnological wells.

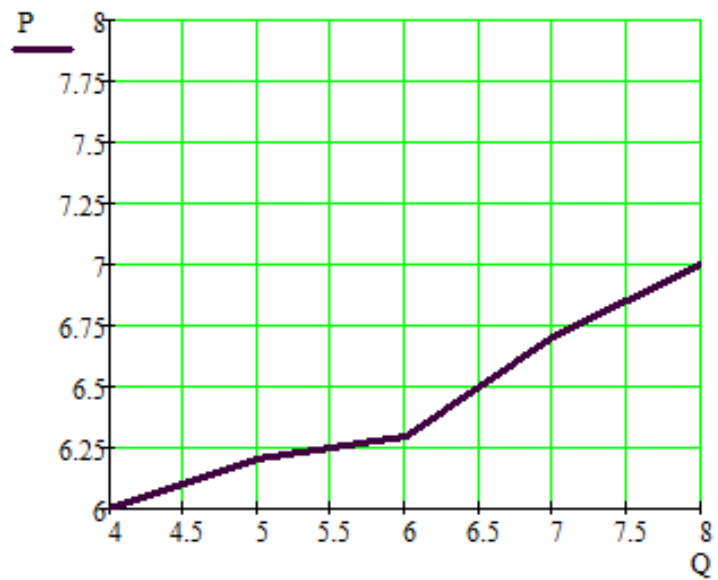

Figure 6: Graphical dependence of pump power consumption (P, $\mathrm{kW})$ on pump delivery $\left(\mathrm{Q}, \mathrm{m}^{3} / \mathrm{h}\right)$ when using the developed device to combat sand eruption and gas content in geotechnological wells.

Figure 6 shows that the use of the developed device to combat sand eruption and gas content in geotechnological wells contributes to significant savings of electric energy consumed by the pump drive, while saving of electric energy consumed for the same received supply amounts to $400 \mathrm{~W}$.

Feasibility study of the developed method and device to control sand and gas content in geotechnological wells equipped with a submersible pump in the conditions of underground leaching mines is carried out by calculating the power consumption, which is presented below.

The annual electricity consumption by the pumping equipment under the proposed option is determined by the formula:

$$
W_{\text {cycle }}=P_{c} \cdot E U F \cdot t \mathrm{kWh} / \text { year }
$$

where: EUF - 0.85 equipment utilization factor over time; $\mathrm{t}$ - pumping equipment runtime relative to the design period, hour / year;

$\mathrm{P}_{\mathrm{c}}$ - calculated capacity of the pumping equipment at a given current:

$$
P_{c}=\sqrt{3} \cdot I_{p} \cdot U \cdot \cos \varphi \mathrm{kW}
$$

where: $I_{p}$ - phase current calculated at the average pump capacity Q [3].

The results of calculation of economic efficiency of the proposed device for combating sanding and gas content in wells equipped with submersible pumps are shown below.

Capital costs: purchase of the proposed device - \$20. Capital costs: purchase of the proposed device - $\$ 20$; commissioning works $(17 \%)$ - \$3.4. The capital costs: purchase of the proposed device - $\$ 20$; commissioning (17\%) - $\$ 3.4$; delivery of equipment $(10 \%)$ - $\$ 2$. The total capital cost is therefore $\$ 25.4$.

Table 1 shows the energy costs for variants at the usual configuration and in the application of our proposed device to combat sand and gas leakage in wells. 
Oybek Kurbonov Mukhammatkulovich, International Journal of Emerging Trends in Engineering Research, 9(3), March 2021,211 - 216

Table 1: Electricity costs by option

\begin{tabular}{|c|c|c|}
\hline Name of items & Dimension & $\begin{array}{l}\text { Numerical } \\
\text { designation }\end{array}$ \\
\hline \multicolumn{3}{|c|}{ Electricity consumption in normal mode } \\
\hline $\begin{array}{l}\text { Amount of } \\
\text { electricity } \\
\text { consumed per year }\end{array}$ & $\mathrm{kWh} /$ year & 40208,4 \\
\hline $\begin{array}{l}\text { Price per kWh of } \\
\text { electricity with } \\
\text { VAT }\end{array}$ & $\$ / \mathrm{kWh}$ & 0,032 \\
\hline $\begin{array}{l}\text { The cost of } \\
\text { consumed } \\
\text { electricity }\end{array}$ & $\$ /$ year & 1286,7 \\
\hline \multicolumn{3}{|c|}{$\begin{array}{l}\text { Electricity consumption under the proposed option and } \\
\text { savings }\end{array}$} \\
\hline $\begin{array}{l}\text { Amount of } \\
\text { electricity } \\
\text { consumed per year }\end{array}$ & $\mathrm{kWh} /$ year & 38198 \\
\hline $\begin{array}{l}\text { The cost of } \\
\text { consumed } \\
\text { electricity }\end{array}$ & $\$$ /year & 1222 \\
\hline $\begin{array}{l}\text { Energy savings per } \\
\text { year }\end{array}$ & \$/year & 64.7 \\
\hline
\end{tabular}

On the basis of research results it was found that the annual power consumption of one submersible pump unit by the existing method in the normal mode is on average 40208.4 kWh per year.

Figure 7 shows the estimated cost of electricity of the basic configuration of the submersible pump and our proposed configuration with a device to combat sand and gas in the wells for years of operation.

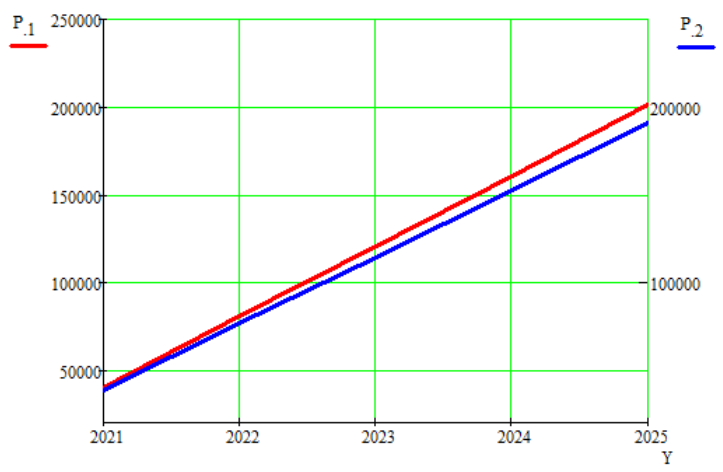

Figure 7: Variation of energy costs for different configuration of the submersible pump. $\mathrm{P}_{1}$-basic configuration, $\mathrm{P}_{2}$-with a device to control sanding and gas content in wells.

When implementing the developed technical solution to combat sand formation and gas content in wells equipped with submersible pumps, energy savings for one unit are as follows:

$$
\Delta W=W_{1}-W_{2} \mathrm{kWh} \text { per year }
$$

From the results of the assessment of economic efficiency it is observed that, the use of the device to combat sand and gas in wells, equipped with submersible pumps can reduce the cost of electric energy by $5 \%$, which in turn helps reduce the cost of pump operation.

\section{CONCLUSION}

The performed research allowed drawing the following main conclusions, which have important scientific and practical significance for the effective operation of submersible pumps: - the developed method and means of combating sand and gas-bearing are characterized by simplicity of design in manufacturing and uncomplicated in operation, and has no negative impact on the environmental situation. This equipment is reliable in operation and prevents accidental shutdown and failure of submersible pumps during suction of liquids containing gases and solid particles.

- the design's effective removal of gas and solids from the product slurry reduces vibration and wear on the equipment. As a result, energy saving is achieved and the premature failure of pumping equipment is prevented.

- as a result of implementation of the developed technical solution and recommendations it is possible to achieve the optimum service life of the pumping equipment up to 7850-8000 machine-hours, and also to increase the equipment efficiency by $20 \%$ and to reduce the power consumption of pumps by $5 \%$.

- the expected estimated annual savings from the implementation of the proposed method and device will be $\$$ 65 per year for one submersible pumping equipment.

\section{REFERENCES}

1. Installations of submersible centrifugal pumps for oil production: International translator. / Edited by V.Y. Alekperov, V.Ya. Kerzhenbaum, "Oil and Gas", 1999 - 611; ill. pp.293-299.

2. Lobachev. P.V. "Pumps and pumping stations" M. stroizdat. 2000.

3. Kozhevnikov N. N. Economics in Power Engineering: Textbook / edited by N. N. Kozhevnikov. - M.: Publishing Center "Academy", 2003. 384 p.

4. A device for separation of solid particles and gas by a submersible centrifugal pump (patent of the Russian Federation №2354821C1, MPK E21B 43/38). The registration date is $08 / 15 / 2007$.

5. A method for controlling sand production in boreholes equipped with a rod pump, and a device for its implementation (patent of the Russian Federation № 2348801, IPC E21B 43/38). Date of registration 10.03.2009. 6. A. Suat Bagci, Murat Kece and Jocsiris Nava, Challenges of Using Electrical Submersible Pump (ESP) in High Free Gas Applications, CPS/SPE International Oil \& Gas Conference and Exhibition in China held in Beijing, China, 8-10 June 2010. SPE 131760.

7. Well Sand Control Technique (patent of the Russian Federation № 2410528, IPC E21B 43/38). Date of registration January 27, 2011.

8. Makhmudov A.M., Khudayberdiev Sh.M. Determination of the main parameters of energy efficiency of pumping units in the technology of underground leaching Nauch. - 
Mining Vestnik of Uzbekistan" - Navoi, 2012. -(3) №50. -C. $73 \div 75$

9. A method and device for combating sand formation and gas content in geotechnological wells equipped with a submersible pump. (patent of the republic Uzbekistan, No. IAP 06089, IPC E21B 43/38). Registration date 30.12.2019.

10. A. Makhmudov, O. M. Kurbonov, M. D. Safarova, Research of the pressure characteristics of the centrifugal water drainage plant of the WCP 25-60G brand, Australian Journal of Science and Technology, Volume 4; Issue 2; June 2020, - p. 279-282

11. Dzhuraev R. U., Merkulov M. V., Kosianov V. A., Limitovsky A. M. Increasing the effectiveness of rock destruction tools when drilling wells with air blowing based on the use of a vortex tube. // Mining Journal. - Izd. "Ore and Metals". - Moscow, 2020. - - №12. p. 71-73. DOI: 10.17580/gzh.2020.12.16 